\title{
AERATION / STRIPPING OF n-BUTYL MERCAPTAN IN AQUEOUS ENVIRONMENT
}

\author{
V.M. MATSIS \\ H.P. GRIGOROPOULOU*
}

\author{
Laboratory of Chemical Process Engineering \\ School of Chemical Engineering \\ National Technical University of Athens \\ 9, Heroon Polytechniou, 15780, Athens, Greece
}

Received: $30 / 5 / 2005$

Accepted: 28/2/2006 *to whom all correspondence should be addressed: e-mail: lenag@chemeng.ntua.gr

\section{ABSTRACT}

Many applications in water quality management have a common key water quality parameter, dissolved oxygen, resulting to the critical role of aeration. On the other hand, in municipal and industrial wastewater, especially where aeration is applied, the presence of volatile organic compounds (VOCs) causes several concerns including a direct threat to humans, partly due to their emission from treatment tanks. $\mathrm{pH}$, temperature and Henry's Law govern VOCs' speciation and consequently their emission characteristics. Limited data and simplifications of available mass-transfer models pose obstacles to a realistic approach, especially in the presence of a chemical equilibrium, for example in the case of mercaptans.

In the present study the importance of oxygen transfer and stripping of a VOC (n-butyl mercaptan) on aeration's overall effectiveness are examined separately. Clean water oxygenation and stripping of mercaptan to an inert gas (nitrogen) were studied aiming to consider mass transfer aspects and to investigate the influence of chemical equilibrium between ionic and neutral form of the target compound in neutral and alkaline solutions. Using appropriate mass transfer relationships (dynamic method), experimental data were analyzed for the determination of overall mass transfer coefficient $\left(\mathrm{k}_{\mathrm{OL}_{\mathrm{O}} \mathrm{O}_{2}} \alpha\right)$ of oxygen. Correlating $\mathrm{k}_{\mathrm{OL}_{\mathrm{O}} \mathrm{O}_{2}} \alpha$ with the corresponding mass transfer coefficient of n-butyl mercaptan_ in neutral solutions (calculated according the model proposed by Matter-Muller et al. [1]), a value of ratio $\beta_{y}$ of 0.566 is found, close to the reported values of other VOCs with similar values of Henry's constant. At alkaline $\mathrm{pH}$ however the conventional simplified model fails to predict realistic values of mass-transfer coefficients. A coupled differential algebraic equation system, based on mass balances, taking into account dissociation of the compound to be stripped and assuming chemical non-equilibrium conditions during stripping, was developed. Reaction parameter $k_{2}$ was calculated with non-linear least-squares analysis. The model predicts satisfactorily the experimental data and it provides a useful tool for the semibatch stripper design in situations where a reversible reaction is involved. At $\mathrm{pH}$ values below 8.5 mercaptan concentration falls exponentially whereas above 10.5 it tends to linearity. The bubble equilibrates and mercaptan transferred depends upon solubility and not diffusivity. Especially after depletion of initial neutral compound, transport depends upon neutral/ionic form speciation. The effectiveness of stripping n-butyl mercaptan, at a given $\mathrm{pH}$, is mainly determined by a proportionality constant considered as "fugacity capacity" (removal effect on the process) and by a reversible reaction rate constant $k_{2}$ (kinetic effect on the process). The "fugacity capacity" is determined by hydrophobicity (i.e. low solubility and high limiting activity coefficient) rather than pure-component volatility (i.e. vapor pressure or boiling point). High limiting activity coefficient promotes mercaptan emission due to established vapor-liquid equilibrium, while the low reaction parameter $\mathrm{k}_{2}$, controls neutral compound quantity. At high $\mathrm{pH}$, where ionic form predominates, experimental data showed that stripping was almost independent of the gas flow rate applied. A strong sensitivity of the model to uncertainty of $\mathrm{Y}^{\infty}$ 
was found: $\mathrm{y}^{\infty}$ controls emission rate and through this the dynamic variations of neutral/ionic concentration profiles whereas reaction rate law parameter $k_{2}$ controls the neutral/ionic transformation and it is the crucial quantity which governs the process at high $\mathrm{pH}$ values.

KEYWORDS: aeration, stripping, n-butyl mercaptan, mass-transfer, chemical equilibrium

\section{INTRODUCTION}

Many applications in water quality management, particularly wastewater treatment, lake and reservoir management, aquaculture, environmental management, biofiltration and water treatment have a common key water quality parameter, dissolved oxygen. As a result, aeration is usually applied in order to maintain good water quality conditions in all cases. Aeration application induces however, apart from the desired mass transfer of oxygen from gaseous to liquid phase, an inverse transfer (emission) of soluble compounds to air.

In the area of municipal and industrial wastewaters the presence of volatile organic compounds (VOCs) cause several concerns including a direct threat to humans, partly due to their emission from treatment tanks, especially where aeration is applied. The $\mathrm{pH}$ and the temperature of the medium and Henry's Law constant govern the speciation of the VOCs and consequently their emission characteristics.

The mass-transfer model for diffused aeration systems, based on the American Society of Civil Engineers (ASCE) oxygen mass-transfer model, was first developed by Matter-Muller et al. [1] and then modified by Roberts et al. [2] and [3], and widely used to estimate emission rates from diffused aeration systems. The ASCE oxygen mass-transfer model, based on the unsteady-state re-aeration technique, uses a global mass-transfer coefficient and a constant saturated dissolved oxygen concentration in the whole aeration tank. A two-zone masstransfer model was developed by Chern and $\mathrm{Yu}$ [4] to estimate the VOC emission rates from diffused aeration systems. Both models estimate emission rates on the base of undissociated organic compounds in the liquid phase. However, data limitations and model simplifications pose obstacles to the development of a realistic approach to the aeration/stripping process. Especially in stripping processes, where a chemical equilibrium exists between various forms of a given compound which is to be stripped, the above models fail to predict system operation. The present study is motivated by the poor understanding of the effect due to the limited available investigations.

Discussed in this work are oxygen and n-butyl mercaptan transfer rates in clean water and the stripping rate of n-butyl mercaptan, a typical odor compound, as part of the overall aeration effectiveness. The relative importance of solution chemistry which affects the stripping operation of n-butyl mercaptan from water is investigated and a model is formulated paying special attention to the equilibrium aspects.

\section{THEORY}

\subsection{Mass transfer of $n$-butyl mercaptan related to the oxygen transfer}

Volumetric mass-transfer coefficient of oxygen. In an agitated vessel where oxygen is sparged, the liquid is perfectly mixed and the oxygen depletion from the rising gas bubble is negligible so that the dissolved-oxygen concentration is described by the relation: $\frac{\mathrm{dC}}{\mathrm{dt}}=\mathrm{k}_{\mathrm{OL}_{\mathrm{O}} \mathrm{O}_{2}} \alpha\left(\mathrm{C}^{*}-\mathrm{C}\right)$

where $\mathrm{k}_{\mathrm{OL}, \mathrm{O}_{2}} \alpha\left(\mathrm{min}^{-1}\right)$ is the volumetric mass transfer coefficient, $\mathrm{C}\left(\mathrm{mol} \mathrm{I}^{-1}\right)$ the dissolvedoxygen concentration in the bulk liquid, and $\mathrm{C}^{*}\left(\mathrm{~mol} \mathrm{I}^{-1}\right)$ the oxygen saturation concentration at the gas-liquid interface. Since the sensor has a finite response time $\left(\mathrm{t}_{90}<10 \mathrm{~s}, \mathrm{t}_{95}<16 \mathrm{~s}, \mathrm{t}_{99}<60 \mathrm{~s}\right)$ the concentration indicated by the sensor, $\mathrm{C}_{\text {sens }}(\mathrm{t})$, is related to the concentration in the liquid $\mathrm{C}(\mathrm{t})$ as:

$$
\frac{d C_{\text {sens }}(t)}{d t}=k_{\text {sens }}\left[C(t)-C_{\text {sens }}(t)\right]
$$

where $\mathrm{k}_{\text {sens }}\left(\mathrm{min}^{-1}\right)$ is a constant, quantifying the response time of the oxygen sensor. Solving simultaneously equations (1) and (2) we obtain: 


$$
\mathrm{C}_{\text {sens }}(\mathrm{t})=\mathrm{C}^{*}\left[1-\frac{1}{\mathrm{k}_{\text {sens }}-\mathrm{k}_{\mathrm{OL}, \mathrm{O}_{2}} \alpha}\left(\mathrm{k}_{\text {sens }} \mathrm{e}^{-\mathrm{k}_{\mathrm{L}} \alpha \mathrm{t}}-\mathrm{k}_{\mathrm{OL}, \mathrm{O}_{2}} \alpha \mathrm{e}^{-\mathrm{k}_{\text {sens }} \mathrm{t}}\right)\right]
$$

Overall mass transfer coefficients proportionality. Mass transfer coefficients for n-butyl mercaptan can be computed from the ratio of the diffusivity of oxygen to that of the compound. It has been shown both theoretically and experimentally ([5], [6]) that the ratio of overall mass transfer coefficients of a volatile organic substance $Y\left(H_{Y}>0.1\right.$, where $H_{Y}$ is the dimensionless Henry's law constant for substance $\mathrm{Y}$ ) and of oxygen $\left(\mathrm{O}_{2}\right)$ is independent of the temperature and of the degree of the turbulence in the water phase. Using the film model this ratio may be expressed as:

$$
\beta_{Y}=\frac{k_{\mathrm{OL}, \mathrm{Y}}}{\mathrm{k}_{\mathrm{OL}, \mathrm{O}_{2}}}=\frac{\mathrm{D}_{\mathrm{Y}}}{\mathrm{D}_{\mathrm{O}_{2}}}=\left(\frac{\mathrm{V}_{\mathrm{c}, \mathrm{O}_{2}}}{\mathrm{~V}_{\mathrm{c}, \mathrm{Y}}}\right)^{\delta} \quad \text { (4) } \quad \text { or } \quad \ln \beta_{\mathrm{Y}}=\delta \ln \left(\frac{\mathrm{V}_{\mathrm{c}, \mathrm{O}_{2}}}{\mathrm{~V}_{\mathrm{c}, \mathrm{Y}}}\right)
$$

where $D\left(\mathrm{~m}^{2} \mathrm{~s}^{-1}\right)$ is the molecular diffusion coefficient, $V_{c,}\left(\mathrm{~cm}^{3} \mathrm{~mol}^{-1}\right)$ is the critical volume, $\beta_{Y}$ $[-]$ is the ratio of overall mass transfer coefficients of compound $Y$ and oxygen as defined in equation (4), $\delta[-]$ is an empirical constant.

\section{Estimation of $n$-butyl mercaptan mass-transfer coefficient by the conventional model}

[1]

The development of the model is based on the following assumptions:

- The gas bubbles flow upward through the liquid in a plug-flow fashion.

- The bulk liquid is completely mixed and the compound exists in neutral form.

- Nitrogen transfer is negligible compared with the mercaptan transfer.

- The nitrogen molar flow rate is constant.

- The mass-transfer process for mercaptan is controlled by the liquid-phase resistance.

According to the conventional model, the concentration of $n$-butyl mercaptan in the liquid

phase as a function of time in a batch reactor is given by the following equation:

$-\ln \frac{\mathrm{C}_{\mathrm{RSH}}}{\mathrm{C}_{\mathrm{RSHo}}}=\frac{\mathrm{QH}}{\mathrm{V}_{\mathrm{L}}}\left[1-\exp \left(-\frac{\mathrm{k}_{\mathrm{OL}, \mathrm{RSH}} \mathrm{aV}_{\mathrm{L}}}{\mathrm{HQ}}\right)\right] \mathrm{t}$

where $Q\left(\mathrm{ml} \mathrm{min}^{-1}\right)$ is the volumetric flow rate, $V_{L}(I)$ is the liquid volume.

2.2 Mathematical model of the stripping system based on mass balances.

n-Butyl mercaptan is dissociated in water according to the following reversible reaction:

$$
\mathrm{C}_{4} \mathrm{H}_{9} \mathrm{SH}+\mathrm{OH}^{-} \underset{\mathrm{k}_{2}}{\stackrel{\mathrm{k}_{1}}{\longrightarrow}} \mathrm{C}_{4} \mathrm{H}_{9} \mathrm{~S}^{-}+\mathrm{H}_{2} \mathrm{O}
$$

The removal of the aliphatic mercaptan from an aqueous system involves mass transfer of the undissociated compound ( $\mathrm{RSH}$ ) from the liquid into the gaseous phase. The $\mathrm{pH}$ increases during the removal, and consequently the equilibrium changes from (RS') to (RSH).

Vapor-liquid equilibrium and the validity of Raoult's law are assumed:

$$
y_{R S H}(g)=\gamma^{\infty} x_{R S H}(I) \frac{P_{o, R S H}}{P_{T}}=\gamma^{\infty} \frac{N_{R S H}}{N_{T}} \frac{P_{o, R S H}}{P_{T}}=m N_{R S H}
$$

where y $(-)$ is the molar fraction in gas phase, $P_{o, R S H}(\mathrm{~Pa})$ is the vapor pressure of $n$-butyl mercaptan, $P_{\mathrm{T}}(\mathrm{Pa})$ is the total pressure, $N$ is the number of moles, $\mathrm{m}\left(\mathrm{mol}^{-1}\right)$ is a proportionality constant which is a "fugacity capacity", $Y^{\infty}(-)$ is the activity coefficient at infinite dilution.

The molar flow rate of $n$-butyl mercaptan $\mathrm{F}_{\mathrm{RSH}}\left(\mathrm{mol} \mathrm{s}^{-1}\right)$ leaving the liquid is:

$$
\mathrm{F}_{\mathrm{RSH}}=\frac{\mathrm{mN}_{\mathrm{RSH}}}{1-\mathrm{mN}_{\mathrm{RSH}}-\mathrm{y}_{\mathrm{w}}} \mathrm{F}_{\mathrm{I}}
$$

$\mathrm{K}=\mathrm{k}_{1} / \mathrm{k}_{2}\left(\mathrm{I} \mathrm{mol}^{-1}\right)$ is the equilibrium constant for reaction $(6), \mathrm{k}_{1}, \mathrm{k}_{2}$ are the reaction rate constants $\left(\mathrm{mol}^{-1} \mathrm{~s}^{-1}\right.$ and s $\mathrm{s}^{-1}$ respectively), $\mathrm{F}_{\mathrm{l}}\left(\mathrm{mol} \mathrm{s}^{-1}\right)$ is the molar flow rate of inert gas, $\mathrm{y}_{\mathrm{w}}(-)$ is the molar fraction of water in gas phase .

$$
-r_{\text {forward }}=k_{1} C_{\mathrm{RSH}} \mathrm{C}_{\mathrm{OH}^{-}} \text {(10.1), } r_{\text {reverse }}=\mathrm{k}_{2} \mathrm{C}_{\mathrm{RS}}{ }^{-} \text {(10.2), } \mathrm{rV}=\mathrm{k}_{2}\left(\mathrm{~N}_{\mathrm{RS}^{-}}-\frac{\mathrm{K}_{\mathrm{eq}}}{\mathrm{V}} \mathrm{N}_{\mathrm{RSH}} \mathrm{N}_{\mathrm{OH}^{-}}\right)
$$


where $\mathrm{r}\left(\mathrm{mol} \mathrm{I}^{-1} \mathrm{~s}^{-1}\right)$ is the reaction rate, $\mathrm{C}\left(\mathrm{mol} \mathrm{l}^{-1}\right)$ is the concentration.

The nonequilibrium unsteady-state mass balance model includes mass balance in liquid phase of neutral and ionic form of n-butyl mercaptan, electroneutrality condition, water equilibrium in liquid and gas phase and a set of initial conditions. This model is described in detail elsewhere [7].

\section{EXPERIMENTAL SECTION}

Oxygenation process: The saturation method is applied with a discontinuous switch from nitrogen to oxygen. Nitrogen is bubbled until the dissolved oxygen falls to almost zero. Then the nitrogen flow is stopped, all bubbles escape from the water and air / pure oxygen is sparged into the reactor, while simultaneously the dissolved oxygen in the water is monitored by a Dissolved Oxygen Probe (WTW Oxi 340i).

Stripping process: n-Butyl mercaptan is removed from its neutral or alkaline solutions in a stirred semibatch reactor in the absence of dissolved oxygen. The $\mathrm{pH}$, gas flow rate and temperature are varied. The liquid is an alkaline solution of $n$-butyl mercaptan and $\mathrm{pH}$ is adjusted by sodium hydroxide.

Apparatus and Procedure. In Figure 1 the experimental setup is presented. The system was operating under isothermal conditions using a thermostatic bath from Julabo.

$\mathrm{A} \mathrm{pH}$-meter $\mathrm{pH} 538$ and an oxygen meter Oxi 340i from WTW were employed for on-line measurements. The total concentration of mercaptan in the liquid was measured by a PerkinElmer 520S UV/VIS Spectrophotometer at $412 \mathrm{~nm}$. The concentration of Butyl mercaptide ion in the liquid system was measured by a Camspec M302 UV/VIS Spectrophotometer at 239nm continuously using a Schlauchpumpe 5260 EPPENDORF peristaltic pump for recirculation. Gas samples were analyzed by a Perkin-Elmer SIGMA 3B Gas Chromatograph either using a sample valve or by injections.

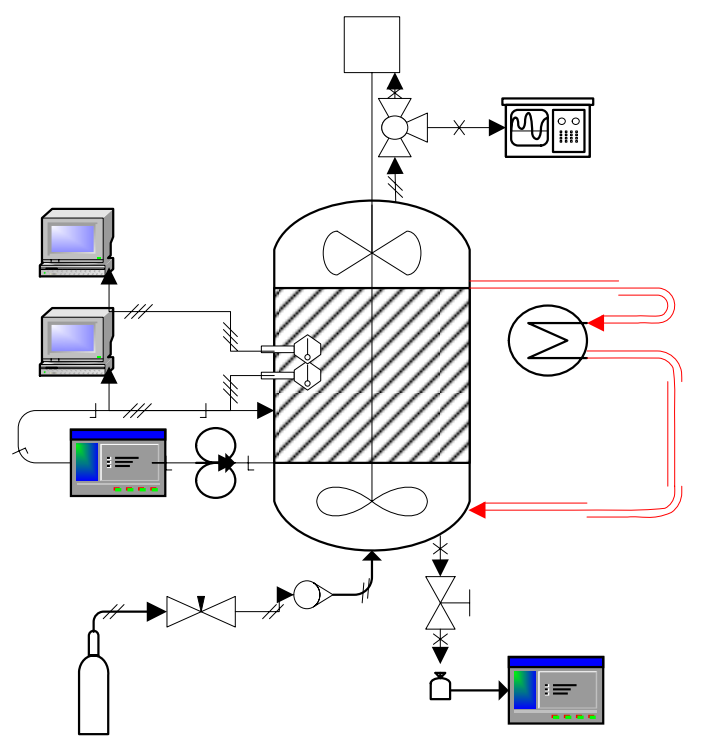

Figure 1. Schematic diagram of the apparatus

\section{RESULTS AND DISCUSSION}

\subsection{Mass transfer coefficient for oxygen and $n$-butyl mercaptan}

After applying least-square fit using equation (3), the $\mathrm{k}_{\mathrm{OL}_{2} \mathrm{O}_{2}} \alpha$ value can be determined from the response curve with an error of less than $2-4 \%$. The effect of temperature on $\mathrm{k}_{\mathrm{OL}_{,} \mathrm{O}_{2}} \alpha$ at four gas flow rates is shown in Figure 2. 


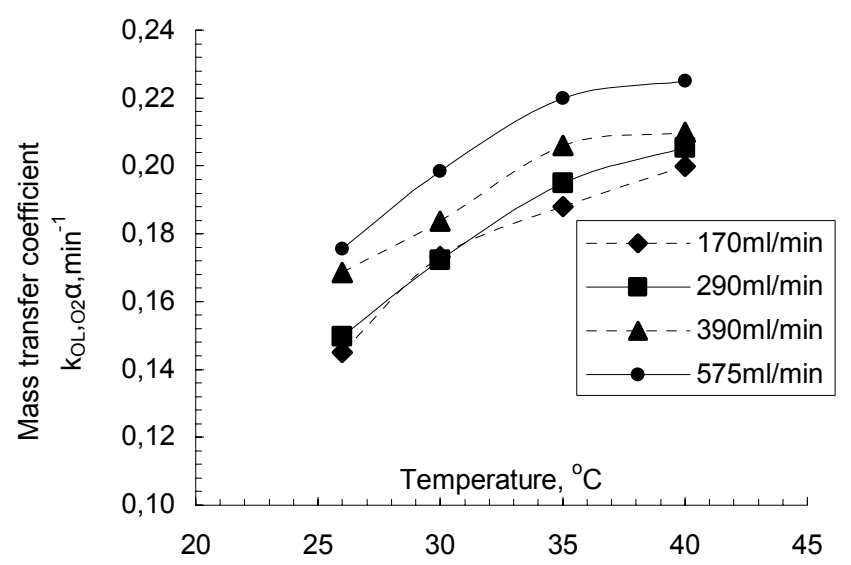

Figure 2. Effect of temperature on $\mathrm{k}_{\mathrm{OL}_{1} \mathrm{O}_{2}} \alpha$ values at $580 \mathrm{rev} \mathrm{min}^{-1}$

It can be seen that the $\mathrm{k}_{\mathrm{OL,}, \mathrm{O}_{2}} \alpha$ value increases with the sparging rate and with temperature, showing a maximum value at $40^{\circ} \mathrm{C}$. This finding is consistent with other studies [8]. In Table 1 are reported results from literature consistent with those from the present study regarding the ratio $\beta_{Y}$.

Table 1. Ratio $\beta_{Y}$ for volatile organic substances and mass transfer coefficients in aeration / stripping experiments

\begin{tabular}{|c|c|c|c|c|c|c|}
\hline \multicolumn{2}{|c|}{ Substance } & $\begin{array}{l}\mathrm{H}_{\mathrm{Y}} \\
(-)\end{array}$ & $\begin{array}{l}\mathrm{k}_{\mathrm{OL}, \mathrm{Y}} \alpha \\
\left(\mathrm{min}^{-1}\right)\end{array}$ & $\begin{array}{l}\mathrm{k}_{\mathrm{OL}_{2} \mathrm{O}_{2}}{ }^{-1} \\
\left(\mathrm{~min}^{-1}\right)\end{array}$ & $\begin{array}{l}\beta_{Y} \\
(-)\end{array}$ & $\begin{array}{c}\mathrm{V}_{\mathrm{c}, \mathrm{Y}} \\
\left(\mathrm{cm}^{3} \mathrm{~mol}^{-1}\right)\end{array}$ \\
\hline \multicolumn{2}{|l|}{ Benzene $^{\dagger}$} & 0.24 & 0.275 & 0.521 & 0.53 & 260 \\
\hline \multicolumn{2}{|l|}{ Toluene $^{\dagger}$} & 0.25 & 0.231 & 0.436 & 0.53 & 316 \\
\hline \multicolumn{2}{|l|}{ Oxygen } & 32.00 & - & - & 1.00 & 74 \\
\hline \multirow{6}{*}{$\begin{array}{l}\text { n-Butyl } \\
\text { mercaptan }\end{array}$} & $\mathrm{Q}=170 \mathrm{ml} \mathrm{min}^{-1}$ & \multirow{4}{*}{0.21} & $7.79 \times 10^{-2^{*}}$ & 0.1451 & 0.537 & \multirow[t]{4}{*}{226} \\
\hline & $\mathrm{Q}=290 \mathrm{ml} \mathrm{min}^{-1}$ & & $8.76 \times 10^{-2^{*}}$ & 0.1498 & 0.585 & \\
\hline & $\mathrm{Q}=390 \mathrm{ml} \mathrm{min}{ }^{-1}$ & & $9.34 \times 10^{-2^{*}}$ & 0.1686 & 0.554 & \\
\hline & $\mathrm{Q}=575 \mathrm{ml} \mathrm{min}^{-1}$ & & $1.03 \times 10^{-1^{*}}$ & 0.1756 & 0.589 & \\
\hline & & & \multicolumn{2}{|c|}{ Average value } & 0.566 & \\
\hline & & & \multicolumn{2}{|c|}{$\begin{array}{c}\text { Relative standard } \\
\text { deviation }\end{array}$} & $4.4 \%$ & \\
\hline
\end{tabular}

${ }^{\dagger}$ Matter-Muller et al. [1]

${ }^{\ddagger}$ The present study $\left(\mathrm{T}=28^{\circ} \mathrm{C}, \mathrm{pH}=7,580\right.$ rev $\left.\mathrm{min}^{-1}\right)$

${ }^{*}$ Calculated at neutral $\mathrm{pH}$ according to equation 6 .

Mass transfer coefficients for n-butyl mercaptan, calculated according to eq. 6 at $\mathrm{pH}=11.5$, together with the predicted values through $\beta_{Y}$ and mass transfer coefficients of oxygen are reported in Table 2.

Table 2. Experimental and estimated volumetric mass transfer coefficients of $n$-butyl mercaptan at various gas flowrates

\begin{tabular}{|c|c|c|}
\hline $\mathrm{Q}, \mathrm{ml} \min ^{-1}$ & Experimental $(\mathrm{pH}=11.5)$ & Estimated \\
\hline 134 & $5.03 \times 10^{-6} \mathrm{~s}^{-1}$ & $1.34 \times 10^{-3} \mathrm{~s}^{-1}$ \\
\hline 200 & $2.00 \times 10^{-5} \mathrm{~s}^{-1}$ & $1.38 \times 10^{-3} \mathrm{~s}^{-1}$ \\
\hline 412 & $3.70 \times 10^{-5} \mathrm{~s}^{-1}$ & $1.54 \times 10^{-3} \mathrm{~s}^{-1}$ \\
\hline 560 & $5.60 \times 10^{-5} \mathrm{~s}^{-1}$ & $1.66 \times 10^{-3} \mathrm{~s}^{-1}$ \\
\hline
\end{tabular}

Comparing the coefficients derived from experimental results with those from oxygen transfer data the failure of the conventional simplified model to predict realistic values of mass-transfer coefficients is concluded. 
This discrepancy could be due to the neglecting of chemical equilibrium between dissociated and undissociated forms of the compound. In the following section the additional chemical reaction term is taken into account in model development.

\subsection{Stripping degree prediction}

Chemical equilibrium conditions. Equation 6 is the design equation of a batch stripper, considering a non-reacting compound in both liquid and gas phase, and has two limiting cases:

- For $\frac{\mathrm{k}_{\mathrm{OL}, \mathrm{RSH}} \alpha \mathrm{V}_{\mathrm{L}}}{\mathrm{HQ}}>1$ (case 1 ) the exponential term becomes zero and therefore it is simplified in the form $-\ln \frac{C_{R S H}}{C_{R S H o}}=\frac{Q H}{V_{L}} t$ (11.1) (Henry's law constant_determination)

- For $\frac{\mathrm{k}_{\mathrm{OL}, \mathrm{RSH}} \alpha \mathrm{V}_{\mathrm{L}}}{\mathrm{HQ}}<<1$ (case 2) the exponential term can be expanded to yield $-\ln \frac{\mathrm{C}_{\mathrm{RSH}}}{\mathrm{C}_{\mathrm{RSHo}}}=\mathrm{k}_{\mathrm{OL,RSH}} \alpha \mathrm{t}$ (11.2) (mass transfer coefficient determination)

The progression of stripping in the batch system can be represented in a diagram_(Figure 3), which relates the two dimensionless quantities $\mathrm{k}_{\mathrm{OL}, \mathrm{RSH}}, \mathrm{a} \mathrm{V}_{\mathrm{L}} / \mathrm{QH}$ (a comparison_of mass transfer rate with the carrying capacity of the saturated exit gas) and $\mathrm{k}_{\mathrm{OL}, \mathrm{RSH}}$ at_(dimensionless form of the mass transfer rate constant). Figure 3 is predicted from equation 6 and can be separated into three ranges: range 1 where $\mathrm{k}_{\mathrm{OL}, \mathrm{RSH},}, \mathrm{V}_{\mathrm{L}} / \mathrm{QH}<0.1$ (case 2 ) and the exit gas is far from saturation, range 2 where

$0,1<\mathrm{k}_{\mathrm{OL}, \mathrm{RSH},}, \alpha \mathrm{V}_{\mathrm{L}} / \mathrm{QH}<5$ and the exit gas is partially saturated and range 3 where $\mathrm{K}_{\mathrm{OL}, \mathrm{RSH},}, \mathrm{V}_{\mathrm{L}} / \mathrm{QH}>5$ (case 1 ) and the exit gas is in equilibrium with the liquid.

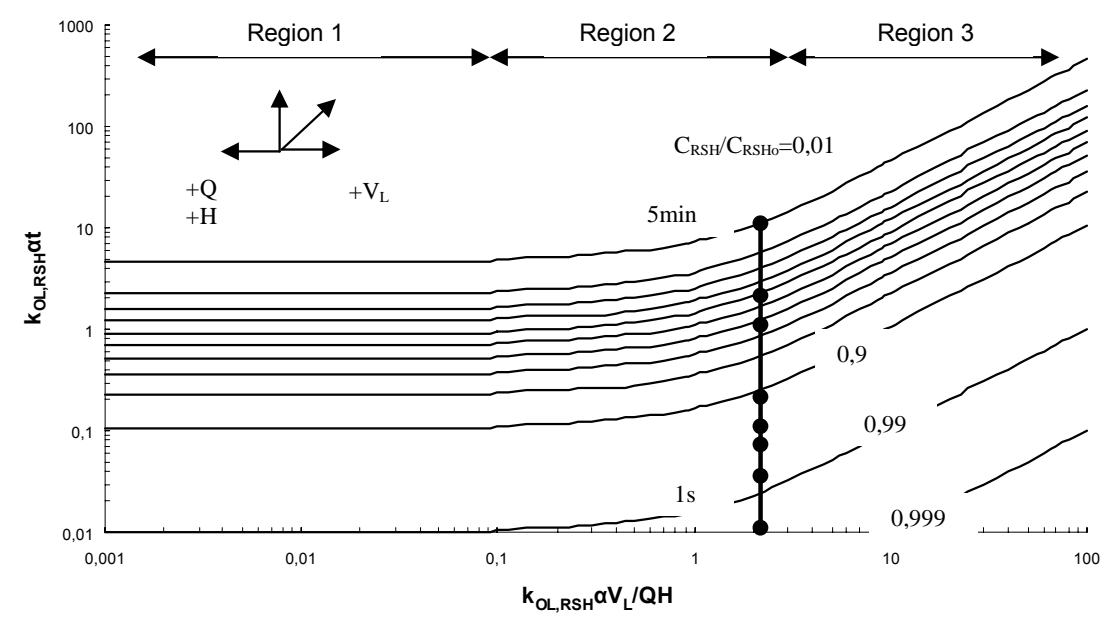

Figure 3. Progression of stripping process in a semibatch system as denoted by the bold vertical line: $\mathrm{H}=0.21, \mathrm{Q}=200 \mathrm{ml} \mathrm{min}{ }^{-1}, \mathrm{k}_{\mathrm{OL}, \mathrm{RSH}} \mathrm{\alpha}=1.38 \times 10^{-3} \mathrm{~s}^{-1}, \mathrm{~V}_{\mathrm{L}}=1.2 \mathrm{I}, \mathrm{T}=28{ }^{\circ} \mathrm{C}$

\section{Chemical nonequilibrium conditions.}

In the presence of a reversible reaction, as it is given by equation 7 , the non-linear algebraic equation system described in section 2.2 can estimate the degree of stripping process in nonequilibrium conditions. The effects of solution $\mathrm{pH}$ and inert gas flowrate on time (dimensionless form) were simulated and shown in Figures 4 and 5 respectively. In these figures a different behaviour is demonstrated concerning the "kinetic" ( $\mathrm{pH}$ dependence) and the "removal" (gas flowrate dependence) part of the total process. At a given pH value the required time increases with increasing degree of stripping. For a given degree of stripping the shape of the curve is similar to a parabolic one. The dotted lines (operation line) indicate the progression of stripping experiments at different $\mathrm{pH}$ values, since the start. At neutral $\mathrm{pH}$ 
value there is a shift towards a higher $\mathrm{pH}$ value, due to reaction 7 , but at strong alkaline conditions the operation line is almost vertical.

On the other hand, the effect of inert gas flowrate is important at low $\mathrm{pH}$ values but its importance is diminished at high flowrates where the neutral/ionic transformation of n-butyl mercaptan becomes the limiting step.
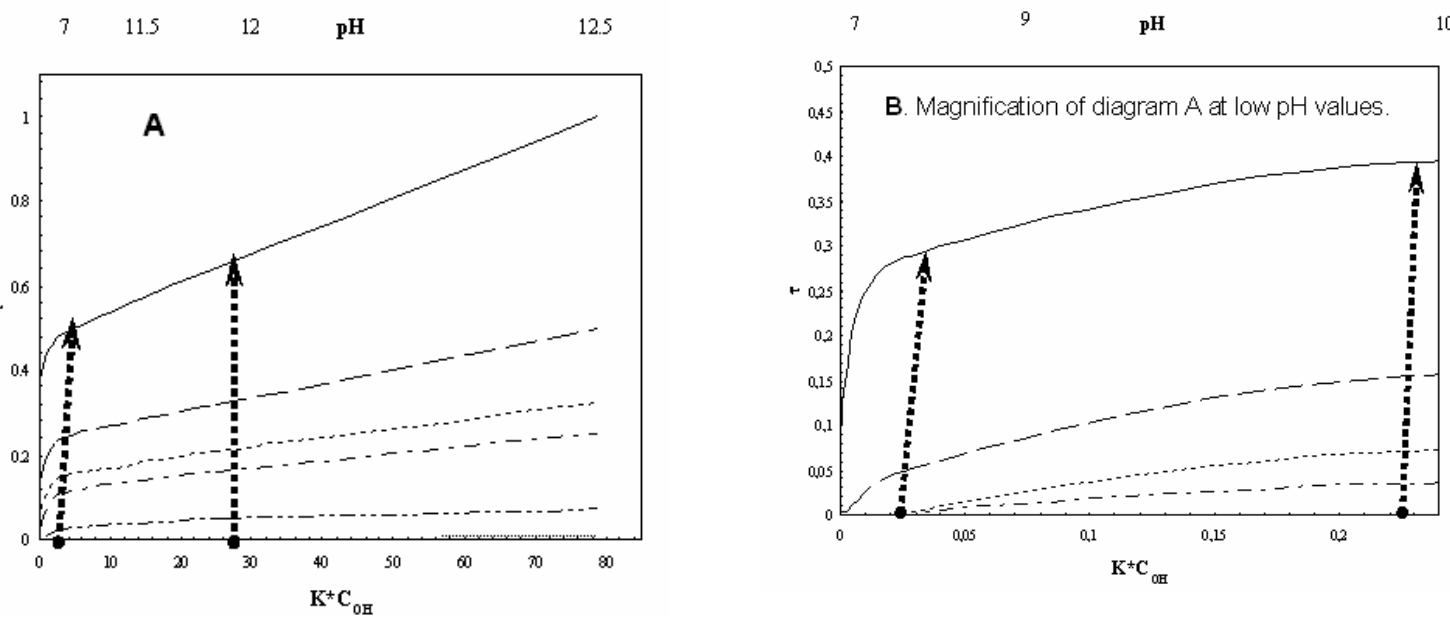

Figure 4. Simulated required time (dimensionless form) for different degree of stripping at varying $\mathrm{pH}$ values (kinetic effect on the process)

$\mathrm{H}=0.21, \mathrm{Q}=200 \mathrm{ml} \mathrm{min}{ }^{-1}, \mathrm{k}_{\mathrm{OL}, \mathrm{RSH}} \mathrm{\alpha}=1.38 \times 10^{-3} \mathrm{~s}^{-1}, \mathrm{~V}_{\mathrm{L}}=1.2 \mathrm{I}, \mathrm{T}=28{ }^{\circ} \mathrm{C}$
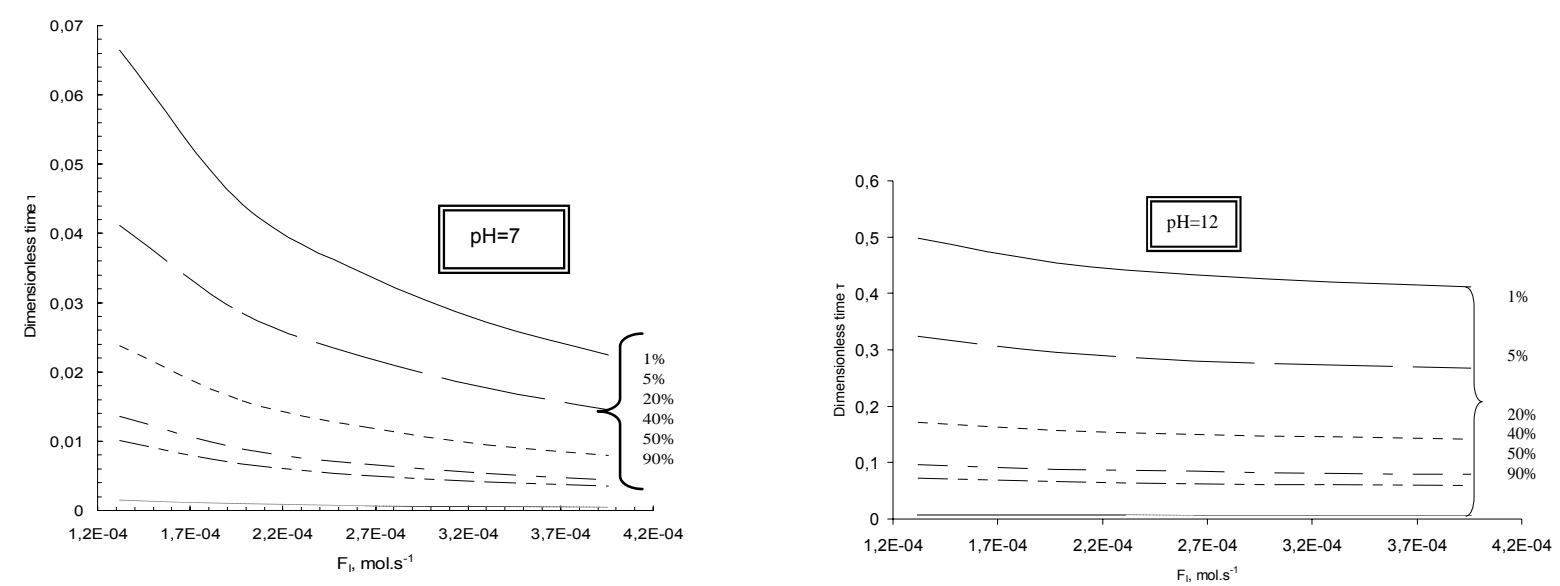

Figure 5. Simulated required time (dimensionless form) for different degree of stripping at varying inert gas flowrate (removal effect on the process)

\subsection{Model calculations and experimental results.}

Model calculations of the stripping system and experimental results (discrete points) at two different gas flowrates and $\mathrm{pH}$ values are presented in Figure 6 . It can be seen that the proposed model (solid line) describes the experiments reasonably well at the $\mathrm{pH}$ range studied. The reaction rate parameter $k_{2}$ is calculated with application of nonlinear leastsquares analysis and found $5 \times 10^{-6} \mathrm{~s}^{-1}$.

\subsection{Dynamic Equilibrium Exploration.}

A series of experiments were performed to characterize the speciation of the target compound. $\mathrm{A} \mathrm{pH}$ of 8.5-10.5 was selected, so that the system be in the intermediate range $\left(8.10^{-3}<\frac{C_{R S}}{C_{R S H}}<8.10^{-1}\right)$. In Figure 7 neutral, ionic and total mercaptan concentration in solution is presented against time. 


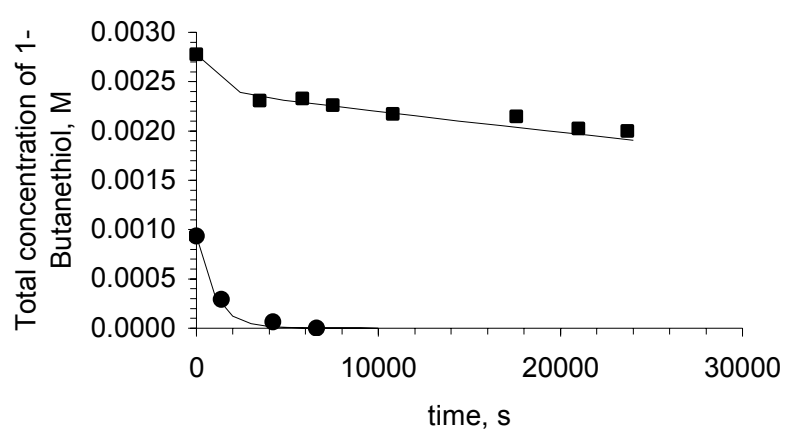

Figure 6. Stripping of $n$-butyl mercaptan in aqueous solutions. $(-)$ : model calculations (•): $\mathrm{Q}=200 \mathrm{ml} \mathrm{min}^{-1}, \mathrm{pH}=8.5, \mathrm{~V}_{\mathrm{L}}=1.0 \mathrm{I}, \mathrm{C}_{\mathrm{RSH}}=0.93 \mathrm{mM}, \mathrm{T}=28^{\circ} \mathrm{C}$

( a ): $\mathrm{Q}=402 \mathrm{ml} \mathrm{min}^{-1}, \mathrm{pH}=11.7, \mathrm{~V}_{\mathrm{L}}=1.2 \mathrm{I}, \mathrm{C}_{\mathrm{RSHo}}=2.78 \mathrm{mM}, \mathrm{T}=28^{\circ} \mathrm{C}$

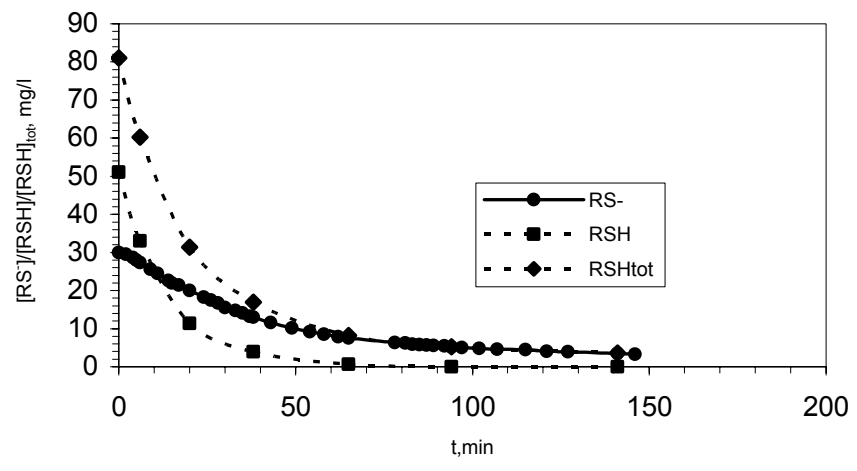

Figure 7. Stripping of $n$-butyl mercaptan in aqueous solutions - Speciation.

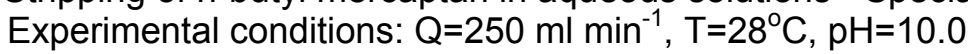

Two regions are distinguished in butyl mercaptide stripping-out. The first is associated with initial available amount of neutral mercaptan emission and lasts until all this amount is stripped out. The second region follows and represents ionic mercaptan transformation to neutral form, which is very slow and dominates the process. As a consequence the neutral mercaptan concentration in the liquid bath cannot be kept at the equilibrium value so an increase in the reaction ratio $Q_{r}=\frac{C_{R^{-}}}{C_{\mathrm{RSH} \mathrm{OH}^{-}}}$happens. The deviation from chemical equilibrium starts 150 minutes for $\mathrm{Q}=60 \mathrm{ml} \mathrm{min}^{-1}$ and after 350 minutes it becomes extremely large $\left(Q_{r} / K=16\right)$. At $Q=250 \mathrm{ml} \mathrm{min}^{-1}$ the deviation from equilibrium conditions starts quite earlier (20 minutes) and after 140 minutes the ratio $Q_{r} / K$ is 26 (Figure 8).

At high $\mathrm{pH}$ values $(\mathrm{pH}>11)$ the term of mercaptan transport through the interface becomes not important compared with the term of reverse reaction rate (less than $1 \%$ through the experiment). At "low" pH values $(\mathrm{pH}<8.5)$ the relation of total concentration of mercaptan vs. time is exponential since it actually represents the concentration of neutral form of the compound. 


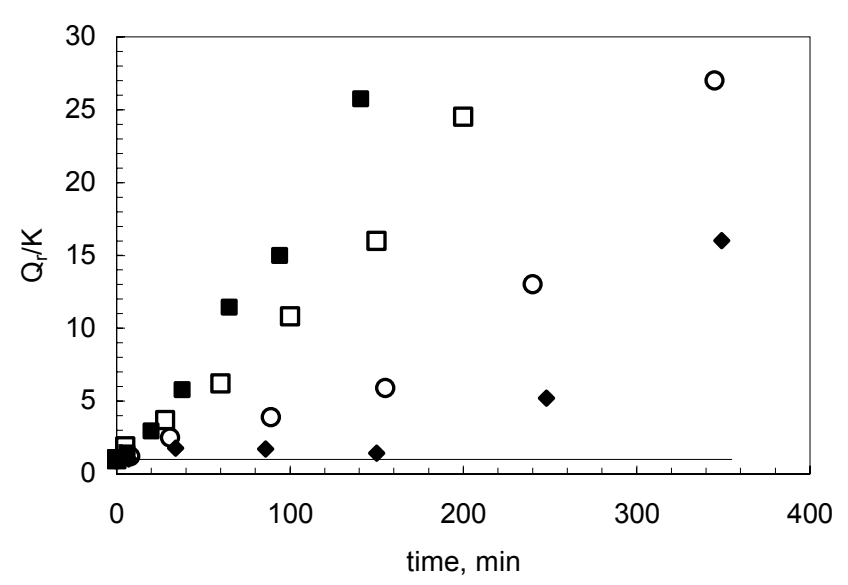

Figure 8. Equilibrium violation in terms of $\mathrm{Q}_{\mathrm{r}} / \mathrm{K}$ vs. time Gas flow rate $(\diamond) 60 \mathrm{ml} \mathrm{min}^{-1},(\circ) 120 \mathrm{ml} \mathrm{min}^{-1},(\square) 180 \mathrm{ml} \mathrm{min}^{-1},(\bullet) 250 \mathrm{ml} \mathrm{min}^{-1}$

At high $\mathrm{pH}$ values neutral mercaptan concentration becomes so small that the forward rate $\left(-r_{\text {forward }}=\mathrm{k}_{1} \mathrm{C}_{\mathrm{RSH}} \mathrm{C}_{\mathrm{OH}^{-}}\right)$becomes insignificant. The remaining reverse rate term governs the mercaptan concentration through butyl mercaptide decay and due to low $\mathrm{k}_{2}$ value the relation becomes linear.

\subsection{Sensitivity analysis.}

The simulated change in neutral/ionic mercaptan quantity and the emission rate resulting from changes in limiting activity coefficient at infinite dilution $\left(\mathrm{Y}^{\infty}\right)$ (presented in Figure 9) exhibits a Gaussian peak which clearly demonstrates the extreme sensitivity of the model simulations to the uncertainty in value of $\mathrm{Y}^{\infty}$. The contribution of $\mathrm{y}^{\infty}$ in the mass balance - based proposed model is undoubtedly fully correlated with $k_{2}$ parameter's. Limiting activity coefficient controls emission rate $\left(F_{\mathrm{RSH}}\right)$ and through this the dynamic variations of $\mathrm{RSH}, \mathrm{RS}^{-}$concentration profiles whereas $\mathrm{k}_{2}$ parameter controls the neutral/ionic transformation and it is the crucial quantity which governs the process at high $\mathrm{pH}$ values.
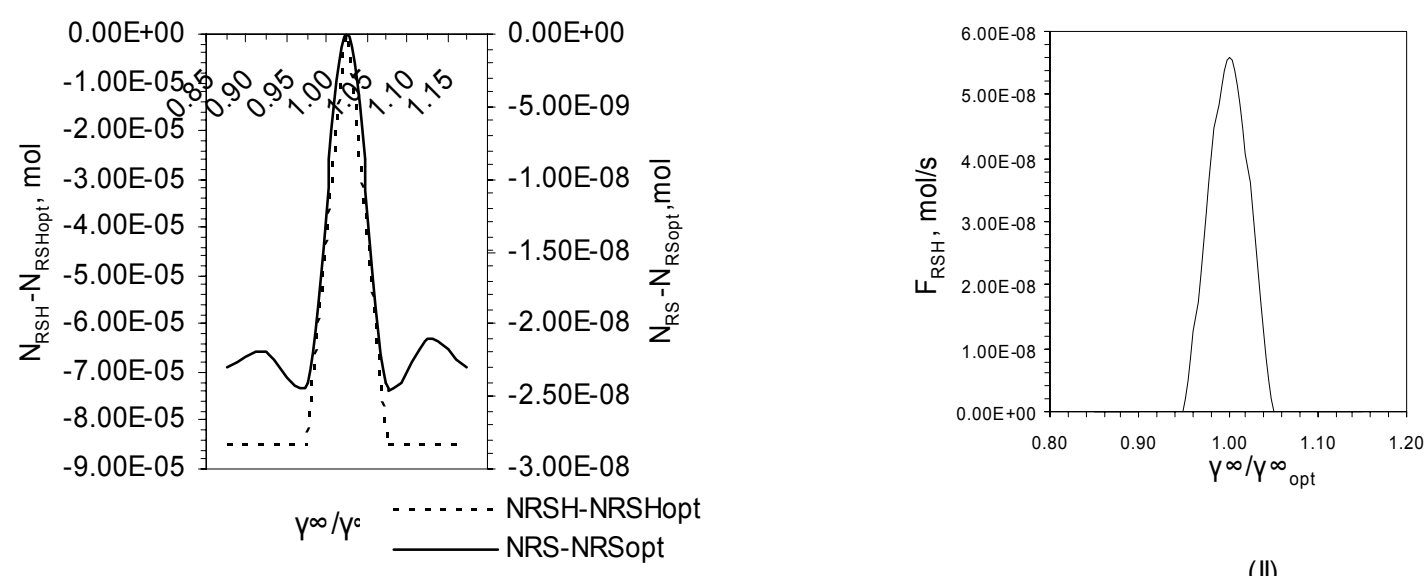

(II)

Figure 9. Simulated changes in (RSH/RS') quantity and the molar flowrate of mercaptan $\left(F_{R S H}\right)$ resulting from change in $\mathrm{Y}^{\infty}(\mathrm{I}$ and $\mathrm{II})$ respectively.

Experimental conditions: gas flowrate $Q=200 \mathrm{ml} \mathrm{min}^{-1}, \mathrm{pH}=8.5$, liquid volume $\mathrm{V}_{\mathrm{L}}=1.0 \mathrm{I}$, initial concentration of n-butyl mercaptan $=0.93 \mathrm{mM}, \mathrm{T}=28^{\circ} \mathrm{C}$

\section{CONCLUSIONS}

This study deals with mass transfer issues concerning clean water oxygenation and n-butyl mercaptan stripping operation focusing in non-equilibrium aspects. 
Using appropriate mass transfer relationships (dynamic method), experimental data were analyzed for the determination of overall mass transfer coefficients of oxygen and n-butyl mercaptan and a ratio $\beta y$ of 0.566 is found with a relative standard deviation of $4.4 \%$, close to the reported values of other VOCs within the same range of Henry's constant.

Data from the stripping system are analyzed in terms of a coupled transport and reaction model including the appropriate thermodynamic equilibrium information.

The effectiveness of inert gas stripping is mainly governed by mercaptan's hydrophobic nature and its neutral/ionic form speciation. Target compound follows an exponential decay at 'low' pH values and almost linear form at 'high' pH values.

A strong sensitivity of the model to uncertainty of $\gamma^{\infty}$ was found: $\gamma^{\infty}$ ('removal' parameter) controls emission rate and through this the dynamic variations of neutral/ionic concentration profiles whereas reaction rate law parameter $k_{2}$ ('kinetic' parameter) controls the neutral/ionic transformation and it is the crucial quantity which governs the process at high $\mathrm{pH}$ values.

\section{REFERENCES}

1. Matter-Muller C., Gujer W., and Giger W. (1981), Transfer of volatile substances from water to the atmosphere, Water Research, 15, 1271-1279.

2. Roberts, P.V., Munz, C., Dandiker, P., Matter-Muller, C. (1984), Volatilization of Organic Pollutants in Wastewater Treatment-Model Studies; EPA-600/S2-84-047; U.S.Environmental Protection. Agency, U.S. Government Printing Office: Washington, D.C.

3. Roberts, P.V., Munz, C., Dandiker, P. (1984), Modeling Volatile Organic Solute Removal by Surface and Bubble Aeration, Res. J. Water Pollut. Control Fed., 56, 157-163.

4. Chern, J.-M., Yu, C.-F. (1995), Volatile Organic Compound Emission Rate from Diffused Aeration Systems. 1.Mass Transfer Modelling, Ind. Eng. Chem. Res., 34, 2634-2643.

5. Tsivoglou, E.C., O'Connell, R.L., Walter, C.M., Godsil, P.J. and Logsdon, G.S.(1965), Tracer measurements of atmospheric reaeration - I. Laboratory studies, J. Wat. Pollut. Control Fed., 37, 1343-1362.

6. Rathbun, R.E., Stephens, D.W., Shultz D.J. and Tai, D.Y. (1978), Laboratory studies of gas tracers for reaeration, J. Envir. Engng Div., 104, 215-229.

7. Matsis, V., Georgantas, D., Grigoropoulou, H. (2006), Removal of $n$-Butyl Mercaptan Using Stripping with an Inert Gas: A Nonequilibrium Approach via Mass Balances, Ind. Eng. Chem. Res., 45, 1766-1773.

8. Panja, N.C. and Phaneswara Rao, D. (1991), Experimental Studies on $k_{L} \alpha$ in a Mechanically Agitated Contactor from Transient Electrical Conductivity Response Data, Trans IChemE, 69(A), 302-307. 